\title{
Serotonin Surge: Intravenous Escitalopram as a Rare Cause of Drug-Induced Aplastic Anaemia
}

\author{
Murtaza Hussain $^{1}$, Katherine Boyer ${ }^{2}$, Anoosha Ponnapalli ${ }^{1}$, Dominic Awuah ${ }^{1}$, Sina Khaneki ${ }^{3}$, Smit Deliwala ${ }^{1}$, Gassan Bachuwa $^{1}$ \\ ${ }^{1}$ Department of Internal Medicine, Michigan State University at Hurley Medical Center, Flint, MI, USA \\ ${ }^{2}$ Department of Pediatrics, Cincinnati Children's Hospital Medical Center, Cincinnati, OH, USA \\ ${ }^{3}$ Internal Medicine Physician at Kaiser Permanente, Lincoln, CA, USA
}

\begin{abstract}
Received: 30/01/2022
Accepted: 01/02/2022

Published: 04/03/2022
\end{abstract}

\begin{abstract}
How to cite this article: Hussain M, Boyer K, Ponnapalli A, Awuah D, Khaneki S, Deliwala S, Bachuwa G. Serotonin surge: intravenous escitalopram as a
\end{abstract} rare cause of drug-induced aplastic anaemia. EJCRIM 2022;9:doi:10.12890/2022_003228.

Conflicts of Interests: The Authors declare that there are no competing interests.

This article is licensed under a Commons Attribution Non-Commercial 4.0 License

\section{ABSTRACT}

Escitalopram is a commonly prescribed medication that has infrequently been implicated in drug-induced thrombocytopenia (DITP) but has never been associated with aplastic anaemia in the literature. We present an extremely rare case of hypoproliferative pancytopenia due to self-administered intravenous (IV) injection of escitalopram. The crux of this case is the unusual trilineage cytopenia. Our patient was managed with steroids and supportive care with subsequent clinical and blood count recovery. This case sheds light on this uncommon but important association.

\section{KEYWORDS}

Intravenous escitalopram, drug-induced aplastic anaemia, hypoproliferative pancytopenia

\section{LEARNING POINTS}

- Escitalopram is an uncommon medication that could lead to drug-induced aplastic anaemia.

- The adverse effects of escitalopram on red cell, white cell and platelet counts may be exacerbated on intravenous administration of the medication.

- Timely diagnosis is vital for the effective treatment of severe aplastic anaemia, avoiding complications and preventing recurrence.

\section{BACKGROUND}

The majority of cases of aplastic anaemias are acquired and idiopathic, the remainder occurring secondary to infections, drugs, nutritional deficiencies, toxin exposure or ionizing radiation ${ }^{[1]}$. Evaluation for underlying aetiology can be challenging; however, drug-induced causes should be considered in any case of acute transient hypoproliferative pancytopenia demonstrating temporal association to new drug exposure. Diagnosis involves recognizing and confirming peripheral blood cytopenias, establishing a hypoproliferative bone marrow, and exploring drug history. Furthermore, recovery from the blood cytopenia on withdrawal of the offending drug and recurrent cytopenia on the reintroduction of the offending drug is crucial to diagnosis.

To the best of our knowledge, this report describes the first case of drug-induced aplastic anaemia (DIAA) secondary to IV administration of escitalopram. 


\section{CASE DESCRIPTION}

A 41-year-old Caucasian man presented to the emergency department (ED) with shortness of breath, confusion and light-headedness. His past medical history consisted of chronic hepatitis C infection, IV drug use, attention deficit hyperactivity disorder (ADHD), depression and anxiety. He admitted to cocaine, marijuana and self-administered IV methylphenidate. His home medications included buprenorphinenaloxone, gabapentin and methylphenidate. Shortly before presentation, he had experimented with his medications, crushing and mixing them with water. It was later found that he unintentionally injected escitalopram intravenously.

Vital signs revealed tachycardia at 115 beats/min, tachypnoea at 25 breaths $/ \mathrm{min}$ and blood pressure of 146/84 $\mathrm{mmHg}$. The patient was afebrile and did not require supplemental oxygen. Physical examination revealed dry mucous membranes, mydriasis and multiple injection track marks bilaterally. Initial laboratory evaluation revealed leukopenia and thrombocytopenia at $0.7 \mathrm{~K} / \mu \mathrm{l}$ and $52 \mathrm{~K} / \mu \mathrm{l}$, respectively, with intact haemoglobin at $15 \mathrm{~g} / \mathrm{dl}$. Further work-up demonstrated mild acute kidney injury and an abnormal liver function panel. The urine toxicology screen was positive for amphetamines, tetrahydrocannabinol (THC) and cocaine. Ultrasound imaging of the abdomen revealed possible haemangioma and mild splenomegaly. The patient also underwent a lumbar puncture, which was unremarkable for infection or inflammation, ruling out meningitis.

He was admitted for acute toxic encephalopathy from an overdose and evaluation of cytopenia. He received IV hydration along with supportive care. His mental status started to improve gradually. By the third day of admission, the patient's haemoglobin had dropped by $3.6 \mathrm{~g} / \mathrm{dl}$ along with worsening thrombocytopenia and leukopenia. Further testing revealed an absolute reticulocyte count of $0.07 \mathrm{M} / \mu \mathrm{l}$, representing $1.6 \%$, suggesting hypoproliferative pancytopenia. He was also noted to have mild elevation of prothrombin time (PT), decreased partial thromboplastin time (PTT) and elevated lactate dehydrogenase (LDH). The pancytopenia continued to worsen, complicated by frank haematuria requiring platelet transfusion. The decision was made to initiate IV steroids, IV methylprednisolone $125 \mathrm{mg}$ on hospital day 4 and $60 \mathrm{mg}$ on hospital day 5, to treat drug-induced myelosuppression. Platelet levels started to improve, reaching levels above $134 \mathrm{~K} /$ $\mu \mathrm{l}$, and haematuria resolved. White cell counts began to trend upwards with release of immature white cells representing adequate bone marrow response. Red blood cell populations and haemoglobin levels also normalized. Renal function also normalized completely. The hospital cytopenia trajectory is summarized in Table 1 with additional work-up provided in Table 2.

As his clinical status optimized, the patient was evaluated by psychiatry and addiction medicine specialists for further outpatient follow-up. Four days after admission, his platelet levels remained at $141 \mathrm{~K} / \mu \mathrm{l}$, white cell counts at $5.8 \mathrm{~K} / \mu \mathrm{l}$, and haemoglobin at $15.8 \mathrm{~g} / \mathrm{dl}$.

\begin{tabular}{|c|c|c|c|c|c|c|c|}
\hline Hospital day & $\begin{array}{c}\text { Platelet } \\
\text { count }(K / \mu \mathrm{l})\end{array}$ & $\begin{array}{l}\text { White blood } \\
\text { cell count } \\
(\mathrm{K} / \mu \mathrm{l})\end{array}$ & $\begin{array}{l}\text { Haemoglobin } \\
\text { (g/dl) }\end{array}$ & $\begin{array}{l}\text { Haematocrit } \\
\text { (\%) }\end{array}$ & BUN (mg/dl) & $\begin{array}{l}\text { Creatinine } \\
\text { (mg/dl) }\end{array}$ & Intervention \\
\hline 1 & 52 & 1.7 & 15.4 & 44 & 33 & 2.0 & \\
\hline 2 & 24 & 15.4 & 13.0 & 36.5 & 36 & 1.6 & \\
\hline 3 & 14 & 9.5 & 12.0 & 35.2 & 22 & 1.0 & $\begin{array}{c}\text { Received platelet } \\
\text { transfusion }\end{array}$ \\
\hline 4 & 13 & 6.6 & 11.8 & 34.8 & 13 & 0.8 & Initiated IV steroids \\
\hline 5 & 27 & 13.6 & 13.3 & 38.5 & 12 & 0.7 & \\
\hline 6 & 61 & 13.3 & 12.7 & 36.8 & 15 & 0.7 & \\
\hline 7 & 89 & 11.3 & 13.2 & 38.5 & 20 & 0.8 & \\
\hline 8 & 134 & 12.1 & 14.4 & 42.1 & 15 & 0.8 & \\
\hline
\end{tabular}

Table 1. Trends over the hospital course of complete blood counts, and renal and liver function 


\begin{tabular}{|c|c|c|}
\hline Hepatitis C genotype: 4 & Viral load: 69,240 IU/ml & Direct Coombs: negative \\
\hline HIV antibody test: negative & $\begin{array}{c}\text { INR: } 1.21 \text { (day } 1) \\
1.13 \text { (day 3) }\end{array}$ & Indirect Coombs: negative \\
\hline Fibrinogen: $269 \mathrm{mg} / \mathrm{dl}$ & D-dimer: 1.57 (H) & Cryoglobulin: none \\
\hline Haptoglobin: $<6.9 \mathrm{mg} / \mathrm{dl}$ & Lactate dehydrogenase: 419 (H) & Ethanol levels: $<10 \mathrm{mg} / \mathrm{dl}$ \\
\hline Reticulocyte count: $1.6 \%$ & Acetaminophen levels: $<10 \mathrm{mg} / \mathrm{dl}$ & Salicylate levels: $<3.0 \mathrm{mg} / \mathrm{dl}$ \\
\hline
\end{tabular}

Table 2. Other relevant laboratory test results

\section{DISCUSSION}

Currently, there is no reported relationship between escitalopram and pancytopenia. However, other selective serotonin reuptake inhibitors (SSRIs) have been cited. Two cases describe the development of aplastic anaemia and neutropenia with fluoxetine use ${ }^{[2,3]}$. This was confirmed with the reduction of peripheral cell lines during initial fluoxetine administration, improvement with its discontinuation, and a reiteration of pancytopenia with re-administration of the drug ${ }^{[2,3]}$. The literature describes oral administration of escitalopram associated with progressive thrombocytopenia over weeks, while IV administration, such by as our patient, had a more rapid course ${ }^{[4,5]}$. This paradigm can be extrapolated to pancytopenia, explaining the findings in our patient. Additionally, the quick recovery of cell lines suggests a transient myelosuppressive process.

The mechanism behind pancytopenia and escitalopram is uncertain, but one theory hypothesizes gene mutations leading to a decrease in the function of P-glycoprotein, a drug efflux pump on CD34+ cells of susceptible patients ${ }^{[6]}$. Another theory postulates gene mutations in glutathione S-transferase theta, an enzyme that metabolizes drugs and usually clears the haematopoietic area of toxic metabolites and other noxious environmental exposures ${ }^{[7]}$.

The incidence of DIAA is exceptionally rare; there are two cases per million in European and North American populations ${ }^{[8]}$. DIAA is further classified as dose-dependent or idiosyncratic. Dose- dependent includes immunosuppressive therapies, chemotherapeutic and other drugs with well-known cytotoxic side effects such as carbamazepine, phenytoin, sulfonamides, chloramphenicol, methimazole, propylthiouracil, etc. ${ }^{[9]}$. However, idiosyncratic anaemia is unpredictable since the sequence of aplasia is uncertain, presenting a challenge for specifying diagnostic criteria. Definitive criteria have been established for DITP ${ }^{[10]}$. Extrapolating these to DIAA, our case met three out of four, suggesting probable correlation with DIAA. Likewise, our patient scored a 4 on the Naranjo Adverse Drug Reaction Probability Scale, consistent with a possible adverse drug reaction ${ }^{[11]}$.

Treatment for DIAA is intuitive, that is, discontinuation of the suspected drug. In our patient, a platelet transfusion was given for symptomatic thrombocytopenia in the form of haematuria. As the cell counts continued to diminish, corticosteroids were additionally administered with eventual improvement. It is uncertain if corticosteroids actually improve platelet levels in DITP[10]. Similarly, the same conundrum exists in DIAA, especially as the three peripheral cell lines had distinct trajectories in their improvement. Perhaps this is the natural course of the disease. Other supportive measures include antibiotics for severe infections in the appropriate clinical context. Allogeneic haematopoietic stem cell transplants are reserved for severe cases of aplastic anaemia ${ }^{[12]}$. Nevertheless, clinicians should consider DIAA in cases of transient aplastic anaemia and should proceed with prompt discontinuation of the suspected drug. 


\section{REFERENCES}

1. Young NS. Acquired aplastic anemia. Ann Intern Med 2002;136(7):534-546.

2. Bosch X, Vera M. Aplastic anaemia during treatment with fluoxetine. Lancet 1998;351(9108):1031.

3. Vilinsky FD, Lubin A. Severe neutropenia associated with fluoxetine hydrochloride. Ann Intern Med 1997;127(7):573-574.

4. Chu C-W, Chao P-C, Chang H-A, Liu Y-W, Chang T-C, Lin P-Y, et al. Escitalopram induced thrombocytopenia reversed after shifting to bupropion in a depressive patient. Aust N Z J Psychiatry 2017;51(10):1055-1056.

5. Puneet D, Ravi K. Escitalopram induced persistent thrombocytopenia: a rare entity. Int J Med Health Sci 2016;5(2):115-117.

6. Calado RT, Garcia AB, Gallo DAP, Falcao RP. Reduced function of the multidrug resistance P-glycoprotein in CD34+ cells of patients with aplastic anaemia. Br J Haematol 2002;118(1):320-326.

7. Babushok DV, Li Y, Roth JJ, Perdigones N, Cockroft JD, Biegel JA, et al. Common polymorphic deletion of glutathione S-transferase theta predisposes to acquired aplastic anemia: independent cohort and meta-analysis of 609 patients. Am J Hematol 2013;88(10):862-867.

8. Al Qahtani SA. Drug-induced megaloblastic, aplastic, and hemolytic anemias: current concepts of pathophysiology and treatment. Int J Clin Exp Med 2018;11(6):5501-5512.

9. Carey PJ. Drug-induced myelosuppression. Drug Saf 2003;26(10):691-706.

10. Aster RH, Bougie DW. Drug-induced immune thrombocytopenia. N Engl J Med 2007;357(6):580-587.

11. LiverTox: clinical and research information on drug-induced liver injury [Internet]. Adverse Drug Reaction Probability Scale (Naranjo) in drug induced liver injury [updated 4 May 2019]. Bethesda (MD): National Institute of Diabetes and Digestive and Kidney Diseases; 2012-. Available from: https://www.ncbi.nlm.nih.gov/books/NBK548069/

12. Kumar R, Bonfim C, George B. Hematopoietic cell transplantation for aplastic anemia. Curr Opin Hematol 2017;24(6):509-514. 